\title{
O uso de gêneros discursivos na elaboração de material para leitura em inglês: uma proposta crítico-reflexiva
}

\author{
Renata Lopes de Almeida Rodrigues \\ FFP / CAp-UERJ
}

\begin{abstract}
Resumo
Este artigo trata do uso de uma abordagem de gêneros discursivos apoiada em Bakhtin (1992), como mediadores da ação humana e motivadores de atividades de leitura de textos em inglês. Algumas concepções de gêneros discursivos são apresentadas para situar o trabalho no escopo da pesquisa na área (cf. Swales, 1990; Bazerman, 2005 e Marcuschi, 2007). Proponho uma apreciação do modelo apresentado por Ramos (2004), a fim de contextualizar o trabalho feito em um projeto de Iniciação à Docência, em uma universidade pública, no Rio de Janeiro. O processo de formação desses futuros professores é orientado por uma visão de discurso como ação social (cf. Moita Lopes, 2003). Uma atividade de leitura elaborada por um dos participantes do projeto é apresentada e analisada a partir desse olhar. A análise aponta para um dos objetivos do projeto: o desenvolvimento da reflexão crítica ao longo do processo de formação inicial do professor.
\end{abstract}

Palavras-chave: Gêneros discursivos; leitura; elaboração de material; reflexão crítica

\begin{abstract}
This article discusses the use of an approach to genres based on Bakhtin (1992), viewing genres as mediators of human action and as elements that motivate reading activities in English. Some concepts of genres are presented in order to place this work in the scope of research within the area of study (Swales, 1990; Bazerman, 2005 e Marcuschi, 2002). I also propose an appreciation of a model presented by Ramos (2004) in order to contextualize the work done in a project in a public university in Rio de Janeiro. The development process of the teachers-to-be in that project is oriented by a view of discourse as social action (cf. Moita Lopes, 2003). An activity designed by one of the participants in the project is presented and analyzed from this perspective. The analysis points to one of the aims of the project: the development of critical reflection through the process of construction of the pre-service teacher.
\end{abstract}

Key-words: Genres; reading; material design; critical reflection

\section{INTRODUÇÃO}

Considerando a relevância do estudo de gêneros discursivos para a construção de conhecimento em sala de aula, este artigo tem por objetivo apresentar e discutir uma abordagem para a elaboração de material didático para o ensino de leitura em inglês, em 
um projeto de Iniciação à Docência, em uma universidade pública no Rio de Janeiro. Nesse projeto, todos os bolsistas estão envolvidos nessa tarefa de elaboração de material instrucional e de reflexão acerca da prática docente.

Entendo que o movimento que parte de gêneros discursivos para o estudo da compreensão escrita vai além do trabalho linguístico discursivo do texto em si, pois o gênero reflete necessidades comunicativas e socioculturais de determinados grupos sociais (Marcuschi, 2002). Portanto, ensinar a ler em uma língua estrangeira inclui a sensibilização dos aprendizes para o fato de que a língua é uma ação social e que os gêneros são formas de "ordenar e estabilizar as atividades comunicativas" (Marcuschi, 2002:19). Além de sensibilizar os aprendizes, nossas ações no referido projeto têm por objetivo também desenvolver a consciência crítica dos professores em formação inicial, que passa pela consciência de nossas identidades profissionais e de nossa responsabilidade social no ensino de uma língua estrangeira (doravante - LE).

Assim como as atividades comunicativas, os gêneros são igualmente inúmeros e de diferentes configurações (oral ou escrito), que podem se materializar, inclusive no meio digital. Isso exige que o professor dinamize o seu trabalho para dar conta de uma gama mais abrangente de gêneros variáveis e mutáveis. Esse caráter mutável dos gêneros é marcado e definido pelos diferentes propósitos comunicativos dos seres sociais. A sala de aula não pode, portanto, ser apenas o local para o trabalho com textos considerados canônicos, sob o ponto de vista pedagógico, como textos literários, narrativas, artigos de jornais e revistas. Textos dessa ordem são tradicionalmente vistos como adequados ao propósito de ensino de uma língua estrangeira. Entretanto, em uma abordagem pedagógica voltada para o aluno, suas necessidades e interesses comunicativos refletem seu modo de vida na contemporaneidade, além de localizá-lo como integrante desse mundo social caracterizado pela variedade, seja esta de ordem tecnológica, cultural, social, interacional ou econômica. Dessa forma, outros gêneros discursivos são bem-vindos para atender a essa nova realidade, por exemplo, textos retirados de um blog ou um chat ou, ainda, um rótulo de produto.

A elaboração de material didático para leitura em inglês discutida aqui segue esses princípios de que usar a linguagem é agir no mundo social e que o discurso nos constitui como membros de um grupo social e de uma cultura, em determinado tempo e espaço. O professor de inglês assume, ou precisa assumir, seu papel de centralidade no 
mundo social, assim como apontam os Parâmetros Curriculares Nacionais ${ }^{1}$ (1998). Segundo Moita Lopes (2003), um dos proponentes dos PCN-LE, é necessária uma visão "do professor de inglês baseada na compreensão do mundo social contemporâneo, no qual o discurso se tornou central" (Moita Lopes, 2003: 32-33).

$\mathrm{O}$ uso de gêneros discursivos diversos (inclusive os digitais) em sala de aula pode permitir ao aluno (que tem acesso às Novas Tecnologias da Comunicação e da Informação ou não) circular por discursos que permeiam o mundo social, os discursos dos quais muitos alunos brasileiros, devido a fatores econômicos ou culturais, ainda encontram-se excluídos, como o da TV a cabo, o da Internet, dos livros, dos jornais ou de revistas científicas (Moita Lopes, 2003). Acrescente-se a isso o fato de que a inserção desses discursos em sala de aula permite ainda que a interação entre professor e aluno promova mais oportunidades de reflexão crítica acerca das esferas da vida privada e da vida pública (Moita Lopes, 2003).

Os licenciandos que participam do projeto aqui descrito estão tendo sua primeira experiência com a elaboração de material instrucional e estão, ao mesmo tempo, construindo suas visões do que vem a ser um professor de língua inglesa a partir dessa perspectiva crítica e reflexiva. Esses alunos estão em processo inicial de construção de suas identidades profissionais, buscando formas de localização no mundo social como aquele que pode promover inúmeras oportunidades de aprendizagem (Allwright, 2005).

Após a discussão da base teórica que ancora o presente estudo, localizarei esta pesquisa dentro do paradigma interpretativista, por fim, discutirei, à luz das concepções de gêneros discursivos, discurso e ensino de línguas, um exemplo de unidade de leitura elaborada por uma das bolsistas do projeto. Esse material é parte dos dados que venho gerando para minha tese de doutoramento ${ }^{2}$. Ressalto que a geração de dados ainda está em andamento e ainda serão submetidos à análise em seu escopo mais amplo. Para fins deste artigo, focalizarei a questão da elaboração de material para leitura a partir do trabalho com diferentes gêneros discursivos.

\footnotetext{
${ }^{1}$ A partir de agora, PCN-LE.

${ }^{2}$ Os dados a que me refiro provêm de gravações dos encontros entre as professoras orientadoras e os bolsistas do Projeto de Iniciação à Docência e de todo o material de leitura elaborado.
} 


\section{GÊNEROS DISCURSIVOS: DEFINIÇÃO}

O conceito de gêneros discursivos que norteia este estudo tem por base a definição bakhtiniana de que são "tipos relativamente estáveis de enunciados” (Bakhtin, [1979] 1997: 279). Marcuschi (2002), com base também em Bakhtin, afirma que os gêneros textuais precisam ser estudados a partir de seu caráter discursivo e enunciativo. Esse autor apresenta parâmetros de diferenciação entre os conceitos e características de tipos textuais (de natureza linguística) e gêneros textuais (de natureza sócio comunicativa). O segundo grupo de enunciados são aqueles que nos interessa aqui, pois são as inúmeras formas tipificadas de enunciados, como a carta, o bilhete, o e-mail, a resenha, a entrevista, o bate-papo por computador, a notícia jornalística, a receita culinária, a história em quadrinhos, a propaganda, etc. (Marcuschi, 2002: 23).

Os enunciados a que Bakhtin ([1979] 1997) se refere são representações da língua em suas formas oral e escrita em quaisquer atividades humanas. Assim como a natureza dessas atividades, os gêneros são heterogêneos e infinitos em sua variedade (Bakhtin [1979] 1997) e isto torna a tentativa de classificação e identificação dos diferentes gêneros uma tarefa cada vez mais complexa. A complexidade envolvida nesta tarefa envolve também a diversidade cultural e social em que vivemos, uma questão que excede o caráter linguístico dos gêneros que circulam no mundo social tanto em português quanto em inglês.

Pode-se apontar como exemplos dessa diversidade de gêneros a existência de categorias distintas, como os gêneros do discurso cotidiano, os gêneros literários e os gêneros retóricos (Bakhtin [1979] 1997). Para Bakhtin, forma e conteúdo são inseparáveis e o social predomina sobre o individual (Todorov, apud Faïta, 2005). Um enunciado, a partir desse conceito, se relaciona a outro, que o antecedeu no discurso, e só pode ser compreendido em um determinado contexto social de circulação, que inclui aquele que o produz (o locutor) e suas escolhas linguísticas. De acordo com Faïta (2005:156), "ele oferece a esse locutor, além disso, o suporte de uma outra manifestação: a de sua aptidão para escolher os meios linguísticos da eficácia verbal". A presença de traços recorrentes nesses enunciados caracteriza, localiza este em determinado tipo, ou gênero.

Similarmente, Bazerman (2005: 23) define gêneros como "ações sociais significativas realizadas pela linguagem, ou atos de fala. Esses atos são realizados através de formas textuais padronizadas, típicas e, portanto, inteligíveis". A partir dessa 
definição, reforçamos a ideia de que proporcionar ao aluno o contato com diferentes gêneros é também proporcionar a este oportunidades de aprendizagem com diferentes “atividades, padrões interativos, atitudes e relações" (Bazerman, 2005: 24).

De maneira geral, usamos gêneros em todas as esferas de nossas vidas, pois os gêneros perpassam e constituem nossas experiências. Interagimos socialmente e nos posicionamos discursivamente através dessas ações sociais tipificadas que ocorrem em situações recorrentes (Miller, [1984] 1994). Como afirma Devitt (2004: 1), "as pessoas reconhecem os gêneros, embora não reconheçam o poder dos gêneros". O poder a que se refere a autora é o poder de auxiliar na comunicação ou de enganar, por exemplo, o poder que exercemos ao usarmos o discurso em contextos socioculturais.

A seguir, apresento uma relação entre gêneros discursivos e o ensino, questão na qual este trabalho se apoia.

\section{GÊNEROS DISCURSIVOS E ENSINO DE LÍNGUA INGLESA}

A aula de inglês, em geral, segue tradicionalmente o enquadre imposto pelo livro didático, suas propostas de atividades e sequencialidade de ações. A questão que pretendo discutir aqui está relacionada a essa maneira de olhar para as funções e ações na aula de inglês como língua estrangeira. Defendo a ideia de que há outras formas de olhar para esse contexto sociocultural, especialmente, a partir da formação inicial do professor.

Segundo Celani \& Collins (2003: 72), muito dessa deficiência está na formação do professor, visão que compartilho e endosso. Para as autoras, há

\footnotetext{
uma visão equivocada do que significa ensinar uma língua estrangeira. Uma atenção desequilibrada para os aspectos puramente teóricos do ensino, ou para seus aspectos puramente técnicos, é a regra em muitas universidades. Esse desequilíbrio parece ser o principal responsável pela construção de uma importante representação que o professor traz consigo: a de que para se tornar um professor de inglês ele deve aprender a usar técnicas de ensino adequadas (Celani, 1988).
}

Portanto, é preciso se voltar para o ensino a partir da perspectiva da formação, como têm feito alguns pesquisadores em relação ao trabalho com gêneros discursivos de maneira crítica. Há muitos estudos sobre o ensino de gêneros textuais no Brasil (Meurer, 2002), mas, segundo Ramos (2004), o planejamento de cursos com essa perspectiva ainda tem avançado pouco. A autora aponta os trabalhos de Cristóvão 
(2002) e Castro (2003) como alguns exemplos do que se tem feito na área, embora com o objetivo de formar professores reflexivos. Esta última questão é, pois, um dos interesses principais do Projeto "Aulas e Material de Leitura”, do qual faço parte.

Portanto, nesta seção, dedico-me a uma breve revisão bibliográfica do que os pesquisadores têm desenvolvido nesse aspecto, vislumbrando entender e refletir sobre nossas ações no projeto, ao elaborarmos material de leitura com base em gêneros e ao estimularmos a reflexão crítica docente como elemento fundador da nossa prática pedagógica. A pesquisa de Castro (2003: 321) tem por foco a reflexão sobre o processo de formação do futuro professor de inglês e a pesquisadora toma por base o seguinte conceito de reflexão crítica:

\footnotetext{
O conceito de reflexão crítica (Kemmis, 1987), por sua vez, refere-se ao processo de subjetivação desses futuros professores, à medida que eles tornaram-se sujeitos em lugar de objetos do processo sócio histórico e, conscientizando-se das distorções presentes em seu discurso, no processo de discussão de suas ações, chegam à transformação de suas ações (Bourdieu, 1989).
}

Esse conceito coaduna com a proposta aqui discutida sobre a orientação de professores em formação inicial em direção às escolhas teórico-metodológicas que fazemos quando elaboramos material, ou seja, como nossas ações e nosso discurso precisam estar em sintonia para que possamos construir novas identidades profissionais.

Ramos (2004) faz uma reflexão sobre as questões que justificam ou que dão suporte teórico à sua proposta de implementação do uso de gêneros em sala de aula. Assim, ela defende, com vigor, que "gêneros textuais são um recurso pedagógico poderoso" (Ramos, 2004: 116), uma vez que podem ajudar o professor das seguintes maneiras:

[1] Oferecem meios de se levantar o que os alunos têm de fazer linguisticamente, ou seja, os discursos que eles precisam ser capazes de compreender e produzir nas modalidades escrita ou falada; e

[2] capacitam o professor a entender por que um texto é do jeito que é, através de considerações sobre seu propósito, seu contexto de situação e de cultura (Halliday \& Hasan, 1989).

(Ramos, 2004: 116)

Essa perspectiva de uso de gêneros norteia o trabalho de ensino de inglês para fins específicos e pode estabelecer um fino diálogo com a proposta de elaboração de material de leitura que fazemos no projeto de Iniciação à Docência, pois o foco não está apenas no desenvolvimento do conhecimento sistêmico, mas também nas questões 
retóricas e sociais, como o contexto sociocultural de produção e circulação dos gêneros discursivos. É importante ressaltar também que o nosso trabalho está ancorado na visão de aprendizagem de Vygotsky (1998) como fruto da co-construção entre aprendizes e professores na interação social.

Ramos (2004) destaca, ainda, a necessidade do professor de fazer um estudo dos traços linguísticos do texto dentro de um determinado contexto, chamando atenção dos alunos para suas funções comunicativas e discursivas, com o propósito de desenvolver o olhar crítico dos aprendizes. Essa mudança de olhar deve ser, segundo essa visão, estimulada e exercitada durante o processo de formação do professor da mesma forma. Quando isso não se efetiva, torna-se inviável ensinar o que não se faz ou aquilo que não se aprendeu a fazer. Analogamente, Moita Lopes (2003: 31) afirma que "não se pode transformar aquilo que não se entende". Se educar é, de certa forma, uma tentativa de entender ou transformar o que se vive, precisamos construir entendimentos sobre os discursos que nos constituem como integrantes desse mundo. Por isso, destaco a importância de se voltar o exercício da reflexão crítica para o aluno de letras, futuro professor, para se criar possibilidades de conexão entre a realidade e o fazer pedagógico consciente e crítico.

\section{A proposta de Ramos (2004) para a aplicação de gêneros em sala de aula: uma reflexão}

Nesta seção, apresentarei brevemente uma proposta de implementação de material voltado para a compreensão escrita em inglês, um trabalho que se assemelha ao que desenvolvemos no Projeto de Iniciação à Docência. Considero relevante tratar dessa proposta aqui, pois ela pode nos ajudar a ver diferentes possibilidades de se trabalhar com gêneros em sala de aula, assim como pode, ainda, orientar o nosso olhar para a elaboração de material para um determinado público-alvo, que pode ser da comunidade interna da universidade ou os futuros alunos de nossos bolsistas quando estes estiverem à frente de suas próprias salas de aula.

A definição de gêneros "como eventos comunicativos, com propósitos compartilhados por membros de um determinado grupo, ou seja, uma comunidade discursiva" (Swales, 1990 - apud, Ramos, 2004), ilumina o trabalho da autora que elaborou a atividade de leitura analisada e apresentada aqui. 
Bhatia (1993) aponta alguns fatores essenciais na análise de um gênero: “o contexto em que se processa a negociação, os papéis sociais dos participantes, os propósitos dessa interação, [...] os aspectos referentes aos vários níveis de realização linguística do texto". Todos esses elementos assumem um papel relevante para o processo de elaboração e implementação de um material baseado em gêneros discursivos, pois tanto o autor da atividade quanto os alunos que passarão pelo processo de ensino/aprendizagem e o autor do texto em si devem ser considerados na interação a partir de suas marcas sociais e identitárias, suas intenções e crenças.

Essa análise do gênero que será utilizado em sala de aula é uma abordagem que permite que o professor tome decisões acerca de que tipo de material poderá ser produzido a partir dali, além de instrumentalizar o professor com informações sobre o gênero e "aspectos fundamentais a ele inerentes, por exemplo, onde esse gênero circula, a que interesses serve, como se constitui” (Ramos, 2004: 116). Assim, o professor pode tratar de questões do nível sistêmico da língua a partir de uma perspectiva discursiva da circulação e produção desse gênero.

Portanto, essa proposta de Ramos (2004) pontua alguns aspectos cruciais para a elaboração das atividades, que parecem bastante úteis e apropriadas ao contexto de elaboração de material feita pelos professores em formação inicial. Considero o contato com tais abordagens uma oportunidade de aprendizagem para esses futuros professores de entrar em contato com um olhar mais crítico para uma das práticas docentes, que é a produção de material.

O quadro abaixo apresenta uma síntese (adaptada) desses aspectos destacados por Ramos (2004: 117-118). Esse quadro servirá também como base para a reflexão do material que apresentarei mais adiante.

\begin{tabular}{|l|l|l|}
\hline \multicolumn{1}{|c|}{ Gênero } & \multicolumn{1}{|c|}{ Função } & Refletindo sobre o aluno \\
\hline Contextualização & $\begin{array}{l}\text { O propósito, audiência, } \\
\text { crenças, valores } \\
\text { institucionais. } \\
\text { Relação língua - função }\end{array}$ & $\begin{array}{l}\text { O aluno pode ser } \\
\text { estimulado a ver o gênero } \\
\text { criticamente }\end{array}$ \\
\hline Estruturas genéricas & $\begin{array}{l}\text { Devem ser vistas como não } \\
\text { prescritivas, mas que } \\
\text { permitam variações que } \\
\text { advêm de fatores culturais } \\
\text { ou individuais. }\end{array}$ & $\begin{array}{l}\text { Capacitar o aluno a } \\
\text { apropriar-se do gênero e } \\
\text { produzir criativamente. }\end{array}$ \\
\hline $\begin{array}{l}\text { Exemplos autênticos e } \\
\text { adequados }\end{array}$ & $\begin{array}{l}\text { A língua é social e } \\
\text { historicamente situada. }\end{array}$ & $\begin{array}{l}\text { Familiarização com textos } \\
\text { que circulam no mundo } \\
\text { social. }\end{array}$ \\
\hline
\end{tabular}




\begin{tabular}{|l|l|l|}
\hline \multirow{3}{*}{$\begin{array}{l}\text { Atividades que promovam } \\
\text { a interação }\end{array}$} & $\begin{array}{l}\text { A interação com o outro no } \\
\text { meio social possibilita e }\end{array}$ & $\begin{array}{l}\text { O aluno se constitui como } \\
\text { indivíduo a partir da }\end{array}$ \\
& facilita a aprendizagem & interação com o outro \\
(Vygotsky, [1987], 2000) & (Bakhtin,[1979] 1992) \\
\hline
\end{tabular}

\section{O CONTEXTO DE PESQUISA E OS PARTICIPANTES}

Atuo como professora de Língua Inglesa em uma universidade pública em São Gonçalo. Trabalho com o curso de formação de professores e fui convidada por uma colega, Isadora ${ }^{3}$, professora de Prática de Ensino de inglês da mesma universidade, a participar de um projeto de Iniciação à Docência, cujo título é "Aulas e material de leitura em inglês". Esse projeto teve início em 2007 e, desde então, tenho atuado como coordenadora auxiliar do projeto, trabalhando na seleção de textos de diferentes gêneros, discussão de textos teóricos da área de Linguística Aplicada e áreas afins, além da orientação aos bolsistas. Nossos encontros são semanais e, durante essas reuniões, discutimos textos teóricos diversos que embasam o trabalho com a produção de material pelos bolsistas.

Os bolsistas do projeto (Thaís e Roberto) são alunos do curso de licenciatura em Letras, com habilitação em Português e Inglês. Na ocasião de elaboração do material analisado aqui, os bolsistas cursavam o $6^{\circ}$ período e $7^{\circ}$ período respectivamente. É o primeiro projeto de pesquisa de que participam e ambos têm pouca experiência em sala de aula, uma vez que atuam em cursos livres de inglês

\section{O MATERIAL DE LEITURA EM FOCO}

O Projeto "Aulas e Material de leitura" tem por objetivo a aproximação do licenciando do contexto de sala de aula. Nesse projeto, especificamente, trabalhamos com os bolsistas uma base teórica de linguagem, gêneros discursivos, ensino e aprendizagem de línguas, leitura, dentre outros, para que eles possam ter fundamentação para a elaboração de material instrucional para a compreensão escrita em inglês. Fazemos também encontros semanais para a discussão desses textos em conjunto. No momento em que eles trazem o seu material de leitura produzido, nós realizamos

\footnotetext{
${ }^{3}$ Os nomes dos participantes, com exceção do meu, foram substituídos por nomes fictícios por questões éticas.
} 
sessões reflexivas sobre aquelas atividades, todos sugerem alterações e partilhamos experiências.

Normalmente, eles escolhem um gênero discursivo e fazem atividades de préleitura, leitura detalhada e pós-leitura, além de proporem também um trabalho com alguma questão do nível sistêmico que seja relevante para o entendimento ou para estimular a construção do conhecimento e visão crítica sobre aquele determinado gênero.

Selecionei apenas uma dessas unidades elaboradas por uma das bolsistas, Thaís, para analisar detalhadamente e refletir à luz dos conceitos apresentados anteriormente.

\section{Refletindo sobre o material de leitura}

Uma vez discutida a base teórica que subjaz o ensino da compreensão escrita em inglês com gêneros discursivos e apresentada a base metodológica em que esta pesquisa se insere, apresento, a seguir, a discussão e reflexão sobre a unidade de leitura dividida em partes para melhor visualização e apresentação.

\section{A atividade de pré-leitura}

Abaixo, destaco a atividade de pré-leitura elaborada para a unidade de leitura intitulada "Cyber-bullying". Para se aproximar do assunto do texto que será lido adiante e para preparar o ambiente de sala de aula para o tema, que é complexo e muito presente na vida social dos jovens, hoje, Thaís coloca uma figura de uma criança se escondendo do computador, acuada e com medo. Thaís optou por ativar, antes do conhecimento de mundo, o sentimento que a imagem sugere.

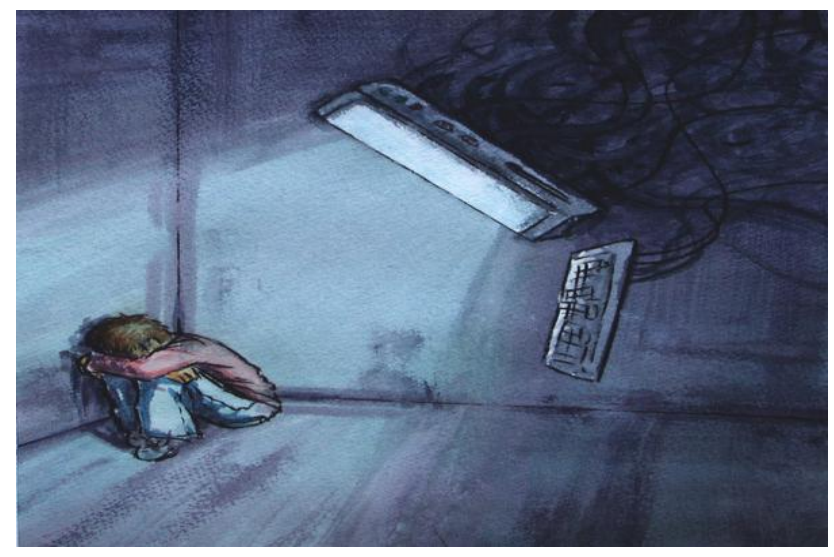


Essa proposta coaduna com a nossa visão e nosso objetivo no projeto de trazer para a sala de aula temáticas que sejam relevantes no mundo social, já que, como discutido anteriormente, a língua é uma forma de ação social. Entendemos, portanto, que o texto não pode ser apenas uma forma de trabalhar com aspectos linguísticos, mas deve oferecer oportunidades de discussão conjunta para a construção de conhecimento comum.

A segunda foto (abaixo) apresenta uma menina também amedrontada com um texto na tela do computador, que a ofende. O objetivo aqui é fazer com que o aluno comece a estabelecer as relações entre as duas situações. Nesse caso, a pergunta "Com que elementos do texto você pode basear sua resposta?" já introduz o trabalho que associa linguagem não-verbal e verbal. Em seguida, a pergunta "Você sabe o que é Cyber-bullying?" é uma tentativa de ativar o conhecimento de mundo do aluno para que o texto não seja a única fonte de informação, mas que estabeleça uma interação e coconstrução de sentidos para o aluno.

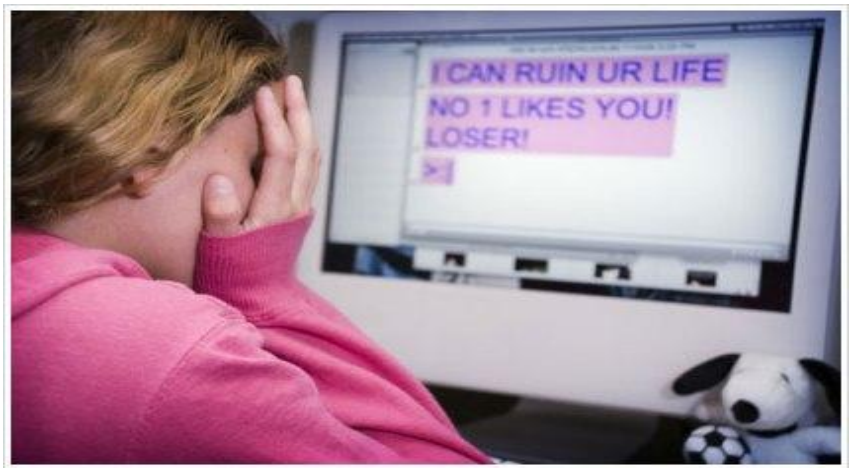

Aponte possíveis ligações entre as duas imagens, refletindo sobre quais atitudes elas comunicam.

A mensagem na tela do computador da menina pode ser considerada ameaçadora? Com que elementos do texto você pode basear a sua resposta?

Você já experimentou situação parecida?

* Leremos um trecho de um texto em inglês que aborda o tema "Cyber-bullying". Você sabe do que se trata? Existe alguma conexão entre a palavra Cyber-bullying e as imagens que lemos há pouco? Por quê?

* Vamos criar hipóteses sobre esse tema antes de ler o texto? Talvez isso possa facilitar a nossa leitura... Responda as seguintes questões, você pode usar palavras em português ou em inglês.

a) Como você definiria o Cyber-bullying?

b) Quem normalmente sofre essa ação?

c) Por que meios o Cyber-bullying acontece? 
O estímulo à criação de hipóteses com as três perguntas ( $\mathrm{a}, \mathrm{b}$ e c) também tem por fim fazer o aluno pensar em uma possível construção do texto a ser lido, nas pessoas envolvidas e nas formas de ação do Cyber-bullying. Essa é uma preparação para a leitura de um texto cuja temática pode estabelecer um contato muito próximo com os alunos, ou por estarem vivendo tal situação ou por conhecerem alguém que esteja vivendo ou praticando isso. É importante dizer que, ao refletirmos sobre o material no encontro do Projeto, nós discutimos também sobre a maneira como isso tem se tornado comum na vida contemporânea e sobre a aula de inglês como uma porta para tratar de assuntos que dizem respeito à vida na sala de aula e fora dela.

\title{
A atividade de leitura
}

Quando o texto do tipo informativo é apresentado, os alunos já tiveram oportunidade de acionar conhecimento prévio sobre o assunto e de fazer inferências a partir da discussão com seus pares em sala de aula. Além de partir do conhecimento linguístico familiar (pedindo para que identifiquem palavras que já conhecem), como o texto é longo, uma proposta foi a de apresentá-lo em parágrafos, para que o aluno tenha oportunidade de pensar sobre a ideia central de cada um deles:

${ }^{*}$ Bem, agora sim vamos ao texto. Você terá duas tarefas durante a leitura do texto:

$11^{a}$ Circule as palavras ou grupos nominais que você conhece o significado.

$2^{2}$ Ao fim de cada parágrafo, com suas palavras, aponte a ideia central ou o que mais te chamou a atenção.

Cyber-bullying

\section{http://en.wikipedia.org/wiki/Cyber-bullying}

\author{
Cyber-bullying defined
}

The National Crime Prevention Council's definition of cyber-bullying is "when the Internet, cell phones or other devices are used to send or post text or images intended to hurt or embarrass another person." StopCyberbullying.org, an expert organization dedicated to Internet safety, security and privacy, defines cyberbullying as: "a situation when a child, tween or teen is repeatedly 'tormented, threatened, harassed, humiliated, embarrassed or otherwise targeted' by another child or teenager using text messaging, email, instant messaging or any other type of digital technology." Other researchers use similar language to describe the phenomenon.

Cyber-bullying can be as simple as continuing to send e-mail to someone who has said they want no further contact with the sender, but it may also include threats, sexual remarks, pejorative labels (i.e., hate speech), ganging up on victims by making them the subject of ridicule in forums, and posting false statements as fact aimed at humiliation. 
Cyber-bullies may disclose victims' personal data (e.g. real name, address, or workplace/schools) at websites or forums or may pose as the identity of a victim for the purpose of publishing material in their name that defames or ridicules them. Some cyberbullies may also send threatening and harassing emails and instant messages to the victims, while other post rumors or gossip and instigate others to dislike and gang up on the target.

Kids report being mean to each other online beginning as young as 2 nd grade. According to research, boys initiate mean online activity earlier than girls do. However, by middle school, girls are more likely to engage in cyber bullying than boys do. Whether the bully is male or female, their purpose is to intentionally embarrass others, harass, intimidate, or make threats online to one another. This bullying occurs via email, text messaging, posts to blogs, and Web sites.

Though the use of sexual remarks and threats are sometimes present in cyber-bullying, it is not the same as sexual harassment and does not necessarily involve sexual predators.

\section{Cyber-bullying vs. cyber-stalking}

The practice of cyberbullying is not limited to children and, while the behavior is identified by the same definition in adults, the distinction in age groups is referred to as cyberstalking or cyberharassment when perpetrated by adults toward adults, sometimes directed on the basis of sex. Common tactics used by cyberstalkers are to vandalize a search engine or encyclopedia, to threaten a victim's earnings, employment, reputation, or safety. A repeated pattern of such actions against a target by an adult constitutes cyberstalking.

Embora os parágrafos sejam longos e aparentemente difíceis para alunos que não tem muito conhecimento da língua inglesa, a tarefa é simples, buscando conscientizá-los de que seu conhecimento de mundo e conhecimento sobre a língua devem ser valorizados e devem servir de base para que a construção de conhecimentos novos e inferências possam ter seu lugar. Após a tarefa de identificação da ideia central, há uma proposta de metacognição acerca da atividade que haviam acabado de realizar:

Que grau de facilidade você atribui a leitura deste texto? Por quê?

Em seguida, por acreditar que a construção do conhecimento e a aprendizagem acontecem na interação com o outro (Vygotsky, 1998), há uma atividade para ser feita em duplas, com a troca de informações e visões sobre os textos lidos:

Trabalhe em dupla com um colega e cheque os seus apontamentos por parágrafos. Conversem sobre as proximidades e diferenças entre as suas anotações. 
Após o trabalho em duplas, o aluno é estimulado a voltar a pensar nas hipóteses que haviam formulado e reavaliá-las, considerando também as informações contidas no texto:

Lembra-se das hipóteses que você formulou antes de ler o texto? Então, retome-as agora. Você deve compará-las com as informações contidas no texto e sua interpretação e responder as seguintes perguntas, retirando um trecho do texto que fundamente sua resposta:

a) Como você definiria o Cyber-bullying?

b) Quem normalmente sofre essa ação?

c) Por que meios o Cyber-bullying acontece?

Nesse momento, o texto já parece estar mais claro e a definição de Cyberbullying bastante discutida. Thaís procura, agora, contextualizar o texto no mundo social, levando o aluno a identificar a fonte e reconhecê-la como confiável ou não, pensar sobre a intenção do autor e na finalidade desse gênero textual e de outros textos que assumem a mesma função (ex. informar, definir).

Como você pôde notar, o trecho "Cyber-bullying defined" conceituou o "Cyber-bullying" através de duas definições. Logo...

1) Essas definições foram inventadas pelo autor do texto? Justifique sua resposta.

2) Qual marca de pontuação aparece nessa parte? 0 que ela indica?

3) Você imagina qual é a finalidade do autor do texto ao fazer uso desse recurso?

4) Você acha que as citações escolhidas dão maior credibilidade ao texto? Por quê? De onde foram tiradas?

5) Que outros textos normalmente usam citações com essa mesma finalidade?

Após essa contextualização, há uma proposta de trabalho no nível sistêmico da língua, com um item que auxilia bastante no entendimento de trechos relevantes para a compreensão do texto - os grupos nominais (Noun phrases):

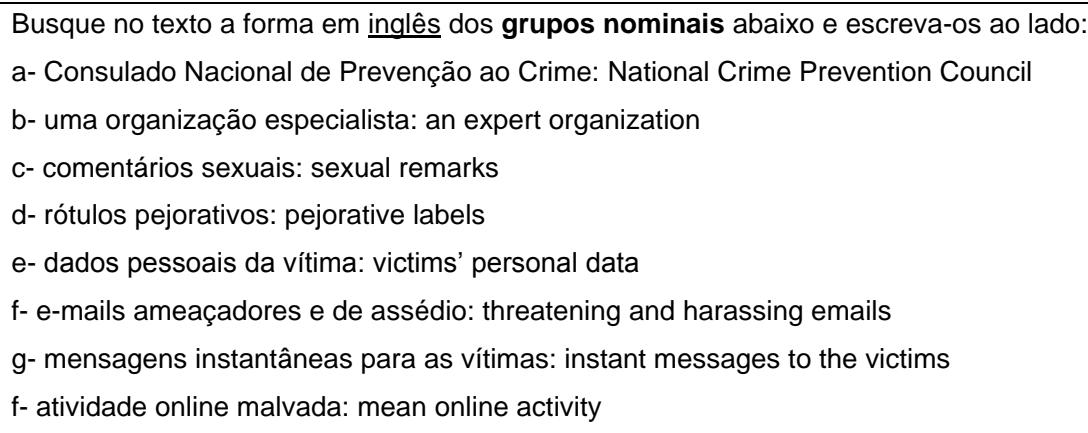

Outra questão relativa ao uso da língua é apresentada como importante para a construção desse gênero discursivo, uma vez que o foco recai sobre os acontecimentos e há necessidade de distanciamento entre o autor e as vítimas - a voz passiva. Essa 
estrutura é bastante comum no texto e vale a pena ressaltá-la e pensar sobre sua função para a construção de sentido no mesmo:

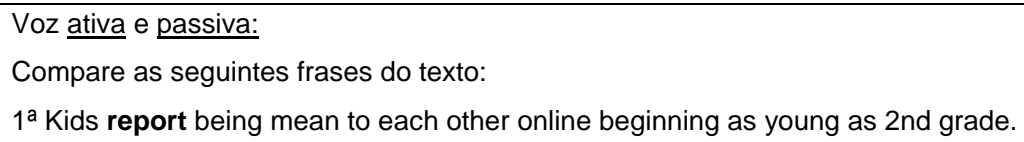

$2^{\text {a }}$ StopCyberbullying.org defined cyberbullying as: "a situation when a child, tween or teen is repeatedly tormented, threatened, harassed, humiliated, embarrassed or otherwise targeted by another child or teenager (...)".

\section{Quais são os sujeitos?}

Quais são os verbos?

- É o sujeito que realiza a ação expressa pelos verbos?

Assim, dizemos que a primeira frase está na voz e a segunda, na voz

Por que a voz passiva é usada?

Temos abaixo alguns casos que requerem a voz passiva, marque um $\mathrm{X}$ naquele que melhor corresponde a situação da $2^{\text {a }}$ frase:

( ) O importante é o que aconteceu e não quem fez acontecer;

( ) Não é conveniente dizer quem é o agente (praticante) da ação;

( ) O agente é desconhecido;

( ) O agente é uma informação importante.

Justifique a sua resposta com base na sua interpretação e nos elementos da frase:

Ainda buscando construir com os alunos um entendimento do texto de forma mais detalhada, propõem-se questões com informações, apresentadas pelo texto, para que eles identifiquem se são verdadeiras, demonstrando seu nível de compreensão até o momento. São elas:

Indique se as frases abaixo são verdadeiras ou falsas, justificando sua escolha com trechos do texto:

a) Praticantes do cyber-bullying podem ocupar a identidade da vítima para difamá-la. ( V )

b) Outros postam rumores e fofocas para que os outros passem a sentir pena da vítima, acabando por gostar mais dela. $(F)$

c) De acordo com pesquisas, as meninas começam essas atividades malvadas antes dos meninos. ( F )

d) Sendo o bullying masculino ou feminino, seu propósito é embaraçar, perseguir e ameaçar outros intencionalmente. ( $\mathrm{V}$ )

e) Cyber-bullying também envolve assédio e perseguição sexual. ( F ) 


\section{A atividade de pós-leitura}

Para que o assunto do texto não ficasse apenas restrito ao gênero da "enciclopédia", com informações conceituais acerca do Cyber-bullying, suas possíveis causas e efeitos, Thaís pensou em usar outro gênero discursivo bastante familiar, em especial aos jovens, para tratar do assunto. Seu objetivo é desenvolver o pensamento crítico e o posicionamento dos alunos diante de uma temática que circula no meio social, particularmente, no mundo contemporâneo.

Para tal, a seção, que normalmente intitulamos pós-leitura, é apresentada aos alunos como "Momento reflexivo", explicitando o enfoque na reflexão crítica. O gênero escolhido foi a "tirinha" ou "cartoon", que tem uma atmosfera cômica como característica principal. Há algumas perguntas para explorar o sentido e o entendimento dos alunos do conteúdo da tirinha. São elas:

\section{Momento reflexivo: =)}

Responda as questões abaixo, baseando-se na tirinha:

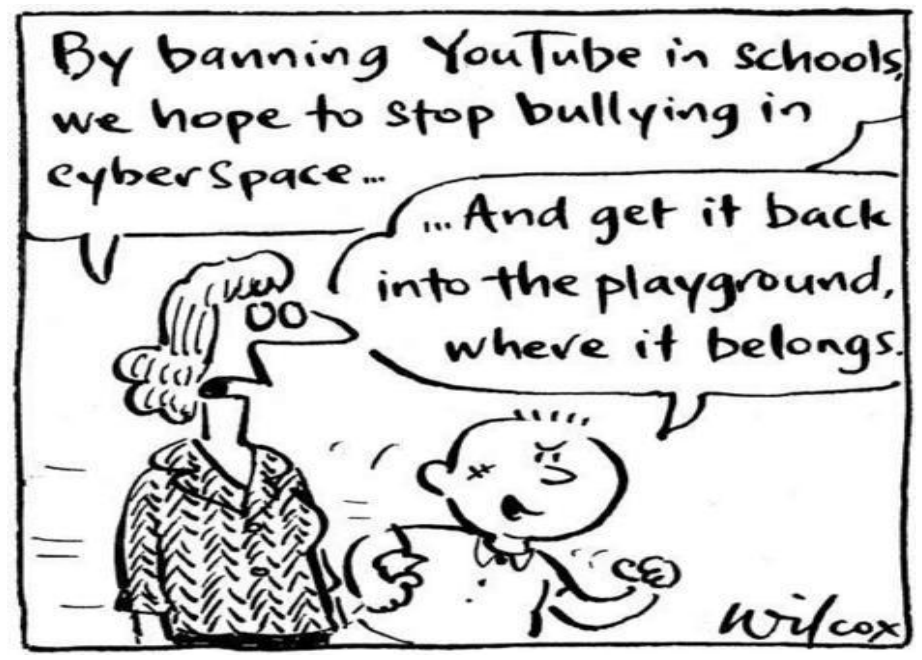

a- Qual medida a escola tomou para evitar o cyber-bullying?

b- Você acha que isso resolveu o problema? Por quê?

Posteriormente, como conclusão da aula, a proposta de trabalho em grupos leva os alunos a uma discussão sobre o tema, levantando questões socialmente relevantes para os estudantes e os estimulando a pensar em possíveis medidas a serem tomadas, em caso de identificação do problema ou medidas de prevenção do mesmo. A seguir, as perguntas finais da unidade: 
Reflita e discuta em grupos:

Você conhece alguém que já sofreu do Cyber-bullying? Como essa pessoa se sentiu? Como uma pessoa nessa situação se sentiria?

Quais são as consequências desse ato para a vida de uma criança ou jovem?

Até que ponto isso pode ser considerado brincadeira ou violência? Quais medidas de punição você acha necessário

nesse caso?

Liste algumas ações que a escola e os pais podem tomar para prevenir o cyber-bullying.

\section{REFLEXÃO FINAL}

O estudo apresentado aqui reflete uma tentativa de discutir e pensar o ensino da compreensão escrita em inglês baseada em gêneros discursivos que circulam no meio social. Considero que buscar entendimentos acerca do processo de ensino e aprendizagem que vivenciamos deve ter raízes na formação inicial de professores. Não é produtivo e tampouco coerente - querer que nossos professores sejam críticos ou estimulem o posicionamento crítico nas escolas se essa visão não está na formação, dentro da academia.

A proposta de análise de uma das unidades de leitura apresentada (baseada em Ramos (2004) consiste em uma maneira de compartilhar como isso vem sendo feito, pois isso nos ajuda a ganhar cada vez mais consciência de que precisamos trabalhar em conjunto, pensando o discurso como forma de ação, de construção de sentidos e de posicionamento no mundo.

Vale ressaltar que esse é um caminho que temos procurado seguir no projeto de Iniciação à Docência, mas que ainda passa pelo processo constante de reflexão do grupo, uma vez que nossas ações não são individuais, pois cada material produzido é submetido à apreciação do grupo, não no sentido de apontar problemas do que foi feito, mas de adequar nossa produção às necessidades do público-alvo e às condições sociais que vivemos no mundo contemporâneo e ao referencial teórico que estabelecemos como coerente com a nossa proposta. Isso contribui para a formação dos licenciandos, além de contribuir também para a reflexão das professoras-orientadoras acerca de suas práticas como formadoras em constante processo de mudança. 


\section{REFERÊNCIAS}

Bakhtin, M. (1992. [1979]). Os gêneros do discurso. In: Estética da criação verbal. São Paulo: Martins Fontes

Bazerman, C. (2005). Atos de fala, gêneros textuais e sistemas de atividades: como os textos organizam atividades e pessoas. In: A. Dionísio \& J. Hoffnagel (orgs.) Gêneros Textuais, tipificação e interação. São Paulo: Cortez.

Brasil. Ministério da Educação e do Desporto. (1998). Parâmetros Curriculares Nacionais - Língua Estrangeira. Brasília: MEC.

Castro, S. T. R. de. (2003). A construção da competência docente do futuro professor de língua estrangeira: um estudo com alunos de inglês de um curso de letras. In: L. Bárbara \& R. C. G. Ramos, (orgs.) Reflexão e Ações no Ensino-aprendizagem de Línguas. Campinas, SP: Mercado de Letras.

Celani, M. A. A. \& Collins, H. (2003). Formação Contínua de Professores em contexto presencial e à distância: respondendo aos desafios. In: L. Bárbara \& R. C. G. Ramos (orgs.). Reflexão e Ações no Ensino-aprendizagem de Línguas. Campinas, SP: Mercado de Letras.

Cristóvão, V. L. L. (2002). Modelo didático de gênero como instrumento para formação de professores. In: J. L. Meurer \& D. Motta-Roth (orgs.) Gêneros Textuais. Bauru, SP: EDUSC.

Devitt, A. (2004) A theory of genre. Writing genres. Carbondale: Southern Illinois University Press. (Capítulo 1)

Faïta, D. (2005). A Noção de "Gênero Discursivo" em Bakhtin: uma Mudança de Paradigma. In: B. Brait (org.). Bakhtin: dialogismo e construção do sentido. Campinas, SP: Editora Unicamp.

Marcuschi, L. A. (2002). Gêneros textuais: definição e funcionalidade. In: A. P. Dionísio et al. (orgs.) Gêneros Textuais \& ensino. Rio de Janeiro: Lucerna.

Meurer, J. L. (2002). Uma Dimensão crítica do estudo de gêneros textuais. In: J. L. Meurer \& D. Motta-Roth (orgs.) Gêneros Textuais. Bauru, SP: EDUSC.

Miller, C. (1984 [1994]). Genre as social action. In: A. Freedman \& P. Medway (Eds.) Genre and the New Rhetoric. 23-42. London: Taylor \& Francis.

Moita Lopes, L. P. (2003). A Nova Ordem Mundial, os Parâmetros Curriculares Nacionais e o ensino de inglês no Brasil: a base intelectual para uma ação política. In: L. Bárbara \& R. C. G. Ramos (orgs.) Reflexão e Ações no Ensino-aprendizagem de Linguas. Campinas, SP: Mercado de Letras, 29-57.

Ramos, R. C. G. (2004). Gêneros Textuais: uma proposta de aplicação em cursos de inglês para fins específicos. The ESPecialist, vol. 25, n2 (107-129). 
Swales, J. M. (1990). The concept of genre. Genre Analysis. Cambridge: Cambridge University Press.

Vygotsky, L. S. (1998). A formação social da mente: o desenvolvimento dos processos psicológicos superiores. São Paulo: Martins Fontes.

\begin{abstract}
A AUTORA
Renata Lopes de Almeida Rodrigues é professora assistente de Língua Inglesa da Faculdade de Formação de Professores da UERJ e do Instituto de Aplicação Fernando Rodrigues da Silveira (Cap-UERJ). Desde 2009, está cursando o doutorado na PUCRio, na área de Estudos da Linguagem. Seu interesse de pesquisa tem sido a formação de professores, orientada pelos princípios da Prática Exploratória. Desde 2007, tem atuado como coordenadora auxiliar do Projeto de Iniciação à Docência "Aulas e material de leitura: uma perspectiva da formação docente em língua inglesa", cujo foco principal é desenvolver com os licenciandos, bolsistas do projeto, materiais voltados para a compreensão escrita do inglês, a partir de um olhar crítico e reflexivo.
\end{abstract}

E-mail: renatalar@uol.com.br 